\title{
Analysing the Curriculum of Epidemiology using Harden's Questions
}

\author{
Mohamed, $K$
}

\begin{abstract}
Introduction: A curriculum is not only a syllabus or content of the statement. A curriculum is about what will be happen in teaching program, about the intension of the teachers and about the methods or the ways of teaching and about the outcomes of the learning. The main aim of the current manuscript was to try to analyse the curriculum according to Harden's method to explore the strengths and weakness of the programme in order to develop the programme.
\end{abstract}

Method: To achieve the objective of the current manuscript, Harden's ten questions of curriculum development framework approach were used to analyse the curriculum.

Result: The analysis of epidemiology curriculum in the Faculty of Public Health and Health Informatics $(\mathrm{PHHI})$ at Umm Al-Qura University, explored that the curriculum has many strong points related to the precise objectives, strong outcomes, a wide range of assessment methods, explicit teaching methods, and there is a well-defined policy for curriculum management, monitoring, and evaluation.

Conclusion: The development of the current curriculum needs continuous monitoring and proper evaluation to support the positive points and to modify the weak points. Analysis of the curriculum will play the key role in developing the curriculum, as the program is essential to graduate epidemiologists in the area where millions of pilgrims come for Hajj annually.

Keywords: Curriculum Analysis, Curriculum Development, Epidemiology, PHHI

\section{Introduction}

A curriculum is not only a syllabus or content of statement. A curriculum is about what will be happen in teaching program, about the intension of the teachers and about the methods or the ways of teaching and about the outcomes of the learning (Harden, 2000). For design a particular curriculum, some fundamental and essential questions should be answered, these questions were proposed by Tyler (1949), and they are: (1) what is the purpose of the curriculum? (2) What educational experiences can be provided to attain these purposes? (3) How can these educational experiences be efficiently organized? (4) How can we determine whether these purposes are being achieved? (Pratt, 1980; Harden, 1986; Posener \& Rudnitsky, 1997; Ten Cate, 1998).

\section{Khalil Mohamed}

Associate Professor, Department of Epidemiology, Faculty of Public Health and Health Informatics, Umm Al-Qura University.

Email:kmismail@uqu.edu.sa; khali72@gmail.com
To reach the rationality rules behind the assessment of curriculum perspectives and to gain the objectives and goals are the critical tasks regarding the detection of the validity of assumptions (Posner, 2004; Ahmed \& Alneel, 2017).

Curriculum analysis is a useful tool that can be utilized to evaluate how the different parts of the curriculum fit together regarding focus and coherence, checking the underlying beliefs and assumptions validity. Also, it is an important step taken by most of the medical schools in seeking justification for curriculum choices and assumptions (Jayawickramarajah, 1987; Ahmed \& Alneel, 2017).

In the last decade, preventive medicine and public health have come to the frontlines in Saudi Arabia. The Faculty of Public Health and Health Informatics (PHHI) was established in 2011 as the third Public Health school in Saudi

Arabia After the Faculty of Public Health in King Saud University for Health and Science and the Faculty of Public Health in Hail University. PHHI has started with seven programmes which became at the top from this point (Mahmoud et 
al., 2016). Epidemiology programme is one of the seven programmes belong to $\mathrm{PHHI}$. The programme of Epidemiology was established in 2012 and starting accepting undergraduate student in 2014 to give student bachelor in Epidemiology, and they are working as epidemiologist after graduation. The programme consists of three years after preparatory year and internship. The curriculum of epidemiology programme was designed in 2012 as traditional curriculum and approved by the council of the University in 2014. The first batch of student now doing the internship and next year will be graduated. The main aim of the current paper is to try to analyse the curriculum according to Harden's method to explore the strengths and weakness of the programme to develop the programme.

\section{Methods}

To achieve the objective of the current manuscript, Harden's ten questions of curriculum development framework approach were used to analyse the curriculum (Harden, 1986; Ahmed \& Alneel, 2017). The method is qualitative, descriptive analysis. This practical tool for approaching curriculum development was proposed in 1986 by Harden in Dundee University in Scotland. Harden's Ten Questions has been used in many universities worldwide due to its optimal validity and reliability (Malik \& Malik, 2002; Swanwick, 2010; Ahmed \& Alneel, 2017).

These ten questions give proper highlighting about the curriculum development and the factors relevant. Also, it is a valid method for planning a course or curriculum, and systematically evaluating the course. During the developmental phase, curriculum if welldeveloped therefore must address Harden's 10 questions (Malik \& Malik, 2002; Swanwick, 2010; Ahmed \& Alneel, 2017). According to Harden's questions, the undergraduate programme of epidemiology in $\mathrm{PHHI}$ has been evaluated. The evaluation included needs assessment, objectives, content, content organisation, educational strategies, teaching methods, assessment methods, educational environment implementation, and curriculum management.

The relationship between the ten questions and the implementation of the epidemiology programme were detected according to the questions responded. Data were collected from different sources and official curriculum documents were also used.

\section{Results \\ Answering Harden's questions}

1) What are the needs in relation to the product of the training programme?

The Faculty of Public health and Health Informatics found in Holy Makkah where million pilgrims and visitors come each year for Umrah and Hajj at the same time as biggest mass gathering around the world. In this kind of environment, a lot of communicable diseases will be expected to spread particularly respiratory infections because of the crowd and mass gathering. This situation needs persistent effort for prevention and control to avoid outbreaks. For this reason, we need specific learning with suitable training to play the proper role in prevention and eradication of the communicable diseases, have the ability to do adequate research, and have proper tools to prepare disease map. The situation needs epidemiologist urgently to fulfil the needs. The main challenges which facing the epidemiologists in Holy Makkah is that: (1) shortages number of epidemiologists (2) distribution of epidemiologists (3) lack of formal training, and (4) limited opportunities. The contributions of epidemiology department in training needs will be as follows: 1Epidemiologists practicing by specialized training in communicable and noncommunicable diseases 2- Epidemiologists in Makkah should be able to function in the community 3- Epidemiologists practicing in Makkah need specialized training to be planners, administrators and decision makers. The reasons for needing this programme divided into three main reasons: Economic reasons, Social/cultural reasons, and National policy developments reasons. The economic reasons included: (1) To decrease the cost of treatment via eradication the communicable diseases in Makkah (2) To create new employment opportunities for national graduates in promising field (3) To decrease the lack of epidemiologists professional in the several health sectors and to decrease the cost of foreign recruitment. The cultural/social reasons included: (1) To minimize the country requirement on foreign epidemiologists and to have qualified citizen epidemiologists who are better to understand Socio-cultural needs of people (2) To spread the health knowledge in the community. The national policy developments reasons included: (1) to increase the application of preventive medicine instead of treatment (2) To promote the community health in Makkah (http:www.uqu.edu.sa). 


\section{2) What are the aims and objectives?}

The program was created as one of the missions of the Faculty because Epidemiology is the fundamental part of Public Health. As the purpose of the college is to work towards preparing professional epidemiologists who will be able to provide holistic quality research based on promoting and maintain health and prevention the illness based on systematic evidence (http:www.uqu.edu.sa).

The main aim and objectives of this program are to (http:www.uqu.edu.sa):

a) Arrange people with health professionals for the growing health service's needs.

b) Clarify the principles of disease causation with particular importance on adjustable factors of the environment.

c) Encourage the request of epidemiology for the disease prevention to health promotion including occupational and environmental health.

d) Encourage the practice of excellent clinical by introducing the concepts of clinical epidemiology.

e) Stimulate a continuing interest in epidemiology.

f) Encourage students to do research which contributes directly to their communities.

\section{3) What content should be included?}

Regarding the plan of the curriculum the curriculum is built on four contents: Teaching, Practical included field work Research and writing thesis, and Internship. In the highlight of teaching, the student will gain all basic knowledge of basic sciences and the epidemiology sciences. The courses are sorting out to make the knowledge logic and easy to understand. The practical contents are matching with the theory of each course and complement to improve and apply the necessary skills. The practice included working in the specific laboratory, gain some essential skills from working in the particular department in the hospitals such as infection control, or working in the field to collect some relevant data or collect different samples. Doing research is the major issue as research has the good connection with epidemiology, the student in the last year will write proposal for his idea and prepare plan for implementing the concept under supervision of the one of the staff. The thesis will be submitted, and the viva with external examiner will approve or reject his work. After finishing the four years, student will go to the internship to apply their knowledge and to gain more skills. The internship is (1) One professional year, divided into three rotation terms (2) Each rotation consists of 4 months in-depth training in one of the department laboratories, hospital, and field (3) In each rotation each student will have two supervisors, one of them from the department.

\section{4) How should the content be organized?}

$\mathrm{PHHI}$ offers five years programme to obtain bachelor in epidemiology, student teaching about 48 courses covering many aspects besides doing research and writing thesis before going to the one-year internship. The phase one is the preliminary year consists of two semesters where students gain knowledge in general sciences including biology, chemistry, genetics, English and scientific English, computer skills, in addition to the Arabic language, Islamic studies. In the phase two, student will gain knowledge and courses related to epidemiology such as medical parasitology, medical entomology, writing methods, molecular biology, microbiology, statistical methods, ...etc as prerequisites for the specific courses of epidemiology which they are coming in the phase three, in the semester 5 to 8 . In phase three, the courses are divided into two types: the first type to support the research skills such as research methodology, epidemiological research, biostatistics ...etc and the second type are specific and pure courses for epidemiology starting from basic epidemiology, hospital epidemiology, clinical epidemiology, pharmacoepidemiology, outbreaks, global health ...etc. The phase four is to research in specific topics related to epidemiology in the semester 8 and under direct supervision of related staff. Phase five is to go for one-year internship.

\section{5) What educational strategies should be adopted?}

The educational strategies which adopted in $\mathrm{PHHI}$ particularly in epidemiology programme including 1- Integration between basic sciences, specific sciences, and behavior sciences 2- community-based education 3teamwork education 4- integration between epidemiology science and research 5integration between theory and practice. (Table 1) 
Table 1: The development of strategies to enhance the epidemiology programme at $\mathrm{PHHI}$

\begin{tabular}{|c|c|c|}
\hline Development & Strategies & Indicators \\
\hline Methods of Teaching & $\begin{array}{l}\text { Depend on the below: } \\
\text { 1. Assignments \& tutorials } \\
\text { 2. Presentations } \\
\text { 3. Roundtable discussion } \\
\text { 4. Case study \& solving problems } \\
\text { 5. Field trips } \\
\text { 6. Individuals \& groups projects } \\
\text { 7. Practical } \\
\text { 8. Research \& thesis submission } \\
\text { 9. Internship }\end{array}$ & $\begin{array}{l}\text { 1. The regular attendance of the } \\
\text { students for the UQU libraries. } \\
\text { 2. Survey about the students } \\
\text { visiting the university website. } \\
\text { 3. Establishment online forum. } \\
\text { 4. Feedback from students using } \\
\text { course evaluation forms. } \\
\text { 5. Field trips report. } \\
\text { 6. Supervisors report. }\end{array}$ \\
\hline $\begin{array}{l}\text { Connect the theory with practical } \\
\text { and fieldwork. }\end{array}$ & $\begin{array}{l}\text { Each subject will be touch in three } \\
\text { locations: } \\
\text { 1. Lecture hall. } \\
\text { 2. Lab. Room. } \\
\text { 3. Field }\end{array}$ & $\begin{array}{l}\text { 1. Attendance sheet. } \\
\text { 2. Field report. }\end{array}$ \\
\hline Research & $\begin{array}{l}\text { The student will choose one topic } \\
\text { to pursue his research in semester } \\
\text { eight under the supervision of } \\
\text { senior staff. }\end{array}$ & $\begin{array}{l}\text { 1.Thesis submission } \\
\text { 2. Oral examination \& discussion. }\end{array}$ \\
\hline Internship & $\begin{array}{l}\text { The students after defenced their } \\
\text { thesis successfully will spend one } \\
\text { year in the fieldwork rotation. The } \\
\text { duration is four months for each } \\
\text { rotation under the direct } \\
\text { supervision of the senior staff of } \\
\text { College and from field workplace. }\end{array}$ & Report from supervisions. \\
\hline
\end{tabular}

\section{6) What teaching methods should be used?}

The following are the teaching methods used:

- Lecture.

- Individual Assignments.

- Tutorial.

- Presentation.

- Round Table discussion.

- Small group teaching.

Teaching tools: Educational tools include slides, overhead projector, exhibitions and most recently PowerPoint presentation.

\section{7) How should assessment be carried out?}

Students will be assessed using different kinds of assessment including:

Written examinations: In any semester, multiple choice and matching tests are using two times in each course and the results of reach $40 \%$ of the final assessment. By the end of each semester, final examination contains mixture of different kinds of questions such as multiple choice, short essays, and matching. semester.

Oral examination: At the end of the

Practical evaluation sheet.
Field trips reports.

\section{8) How should details of the curriculum be} communicated?

In the first start of each course, students give orientation about the containing of the course, aims and objectives, methods of teaching, techniques of assessment, the available resources and other information from the corresponding course coordinator carefully. The programme has brochure with full details about the programme distributed to students. Another leaflet regarding the aspects of training plan and the distribution of groups included in this leaflet.

Discussion group included all the students and academic coordinator is available to answer all students' inquiries and solve the urgent problem.

9) What educational environment or climate should be fostered?

During study in $\mathrm{PHHI}$ students are found attractive environment for learning and for 
gaining knowledge and for enhancing the skills in the practical particularly in the wellestablished laboratories. Social and cultural life are found, students, organized themselves in different clubs, and there are many activities, but these need more support.

\section{0) How should the process be managed?}

The educational process in, general, is managed by the university council, $\mathrm{PHHI}$ dean, vice deans faculty board, curriculum committee and course committee. One of the staff supervises each group of student. The committee of curriculum is responsible for establishing and determining the policy of the curriculum. The course committee responsible of the course and reported to the curriculum committee.

\section{Discussion}

The advantage of Harden 10 questions approach described go beyond the classical focus of goals, educational strategies, and the outcomes. It may be that the organizational impact of curriculum analysis will be of more long-term utility rather than the simple enhancement of curricular material. The strength of the current study is that analysis was achieved according to Harden 10 questions, which is very well-established and intellectualized (Malik \& Malik, 2002; Swanwick, 2010; Ahmed \& Alneel, 2017). This study demonstrated the applicability of this approach to curriculum analysis in setting an innovative medical curriculum.

The essential structures of the curriculum based on the integration of education system and teaching strategy. The Medical School is dedicated to improve the competition between students and supporting their academic and educational needs, give the trust for pursuing study and intellect the social accountability (Arzuman, 2011).

Assessment is necessary to process for quality assurance, which has been termed as equivalent to clinical audit and allows the curriculum to progress and continuously improve in response according to trainee's needs, society and institutions (Morrison, 2003).

There are different methods made the strategy of evaluation very strong. However, regular feedback collecting from trainers or student would be helpful mainly, if there was a systematic method of intervals such as consultants, clinical and educational supervisors, directors of training programme whose advice and comments would be valuable in the evaluation. This could be organized by collecting response through surveys either online or by organising meetings which consultants would be invited and encouraged to give comments to designers of the curriculum. Additionally, external examiners, particularly the directors of the similar programme in institutions which based in other countries, would probably be able to contribute helpfully with their comments to these assessments (Laskaratos et al., 2014).

\section{Conclusion}

The development of the current curriculum needs continuous monitoring and proper evaluation to support the positive points and to modify the weak points. Analysis of the curriculum will play the key role in developing the curriculum, as the program is essential to graduate epidemiologists in area where millions of pilgrims come for Hajj annually.

1. The programme has numerous strong points on which to build in terms of expanding its reach and opportunities for job placements, internships, and ultimately postgraduate studies to produce fully-qualified epidemiologists.

2. The specification of the disciplines seems adequate.

3. Development of epidemiology skills requires good practical training, review of epidemiological scenarios, cases studies, discussion of analytical approaches, and data analysis.

4. More time and practical training are needed if the intention is to be building epidemiological skills that can be applied to any health field.

\section{Financial support and sponsorship}

Nil.

\section{Conflicts of interest}

There are no conflicts of interest.

\section{References}

Ahmed, Y. A. \& Alneel, S. (2017) Analyzing the curriculum of the faculty of medicine, University of Gezira using Harden's 10 questions framework. J Adv Med Educ Prof, 5(2), pp. 60-66. 
Arzuman, H. (2011) Undergraduate Medical Curriculum of Universiti Sains Malaysia in terms of Harden's Ten Questions of Curriculum Development. South-East Asian Journal of Medical Education, 5(2).

Faculty of Public Health and Health Informatics. Umm AL Qura University. Epidemiology Programme Documents. Available from: http:www.uqu.edu.sa

Harden, R. M. (1986) Ten questions to ask when planning a course or curriculum, Medical Education; 20, pp. 356-365.

Harden, R. M. (2000) The integration ladder. A tool for curriculum planning and evaluation. Medical Education, 34, pp.551-557.

Jayawickramarajah, P. T. (1987) The Analysis of Medical Curriculum. Med Teach, 9(2), pp. 167-78.

Laskaratos, F. M., Gkotsi, D., Panteliou, E. A. (2014) critical review of the core medical training curriculum in the UK: A medical education perspective. Journal of the Royal Society of Medicine Open, 5(1), pp. 1-8.

Mahmoud, M. A., AL-Zalabani, A. H., \& Abdulrahaman, K. A. (2016) Public health education in Saudi Arabia: Needs and challenges. Medical Teachers, 38, pp. S5S8.

Malik, A. S. \& Malik, R. H. (2002) The undergraduate curriculum of Faculty of Medicine and Health Sciences, Universiti Malaysia Sarawak in terms of Harden's 10 questions. Med Teach, 24(6), pp. 616-621.

Morrison, J. (2003) ABC of learning and teaching in medicine: evaluation. BMJ, 326, pp. 385-387

Posener, G. J. \& Rudnitsky, A. N. (1997) Course Design: A Guide to Curriculum Development for Teachers, 5th edn (New York, Longman).

Posner, J. G. (2004) Analyzing the curriculum. 3rd ed. Ohio, USA: McGraw-Hill Humanities Social, pp. 315.

Pratt, D. (1980) Curriculum Design and Development (New York, Harcourt Brace Jovanovich.

Swanwick, T. (2010) Understanding Medical Education: Evidence, Theory and Practice. New Jersey: Wiley-Blackwell, pp. 336-351.

Ten Cate, Th. J. (1998) Curriculum: A pragmatic concept description, Bulletin Medisch Onderwijs, 17, pp. 18-30. 